\title{
GESTÃO ESPORTIVA: NOVOS RUMOS PARA 0 FUTEBOL BRASILEIRO
}

\author{
Rafael Valente \\ Graduando em Jornalismo na Universidade Presbiteriana Mackenzie \\ E-mail: jornalismo.rafael@gmail.com
}

Maurício C. Serafim

Doutorando em Administração de Empresas na FGV-EAESP

E-mail: serafim@gvmail.br
No Brasil, ao se abordar a administração do futebol, é obrigatório abordar um grande problema que afeta quase todos os clubes do país: o baixo grau de profissionalismo na gestão. Ele é apontado como o principal fator da crise financeira e estrutural dos clubes, que, se resolvida, poderia melhorar significativamente 0 desempenho deles fora de campo. Pelo menos essa é a opinião do diretor do programa Super Bola, do grupo Pão de Açúcar, José C arlos Brunoro, e do diretor da FGV-Projetos, Antônio Carlos Kfouri Aidar.

Ambos concordam que é necessário mudar a forma como os clubes são geridos atualmente e que 0 debate deve ser iniciado pelo que eles chamam de "profissional ização do departamento de futebol". Isso significa remunerar profissionais que possam estudar os problemas e administrar o futebol como uma empresa. Nesse caso, eles citam o futebol europeu como o grande exemplo de administração, principalmente a Inglaterra, onde há clu- bes como o Manchester United, 0 Arsenal e agora o Chelsea.

A solução para os problemas, porém, não é tão simples quanto pode parecer à primeira vista. Exigiria dos clubes mudanças significativas no âmbito nacional e que surtiriam efeito apenas a longo prazo. Entretanto, mantendo-se a atual conjuntura, a tendência é se ter cada vez mais campeonatos com nível de qualidade questionável, com estádios vazios e comércio intenso de venda de jogadores para o exterior. É isso que apontam José Carlos Brunoro e Antônio Carlos Kfouri Aidar, conhecedores da área e que fal am com autoridade sobre o tema. Ambos têm um histórico de pesquisa e atuação importante no campo da gestão esportiva.

José C arlos Brunoro, 56 anos, formado em Educação Física pela Faculdade de Santo André, foi jogador e treinador de vôlei, teve sua primeira experiência como diretor esportivo na equipe da Pirelli e foi um dos diretores da co-gestão Palmeiras-
Parmalat, considerada a parceria mais bem-sucedida do futebol brasileiro.

Antônio Carlos Kfouri Aidar tem 53 anos, é formado em Administração de Empresas na FGV-EAESP e mestre em Economia pela Michigan State University. É o coordenador do Programa Especial de Gestão de Esportes na FGV-EAESP e autor do livro A nova gestão do futebol, e um dos poucos a tratar do tema no Brasil.

Devido à importância desse tema, a RAE-revista de administração de empresas convidou essas duas personal idades para debater sobre gestão esportiva dos clubes e os rumos do futebol brasileiro. A seguir são oferecidos trechos de suas entrevistas.

\section{JOSÉ CARLOS BRUNORO}

Em sua opinião, quais são os problemas do futebol brasileiro?

O grande problema do futebol brasileiro gira em torno da questão do profissionalismo. Há clubes que são 
administrados com baixo grau de profissionalismo e outros que já se encaminham para um grau maior. 0 profissional ismo não está relacionado necessariamente com o fato de 0 clube assumir uma gestão empresarial, mas em se ter uma postura profissional, ter em posições estratégicas profissionais competentes do mercado, que possam exercer a função com competência. Por isso, acredito que a grande questão é adotarmos o profissionalismo.

\section{Podemos dizer que a crise dos clu- bes é essencialmente uma crise de gestão?}

Normalmente se afirma que temos um problema de legislação - a Lei Pelé - que impõe limites aos clubes. Diferentemente, acredito que o problema não está relacionado com a legislação, mas com a gestão. Isso porque é a gestão do clube que está ao nosso al cance e na qual podemos atuar diretamente. A legislação impõe normas e limites, e a sua modificação escapa ao nosso controle e é imprevisível. Na gestão, podemos realizar mudanças e melhorias de todos os processos com certo grau de liberdade. Grande parte da crise financeira na qual a maioria dos clubes está envolvida é devida à má gestão, fazendo com que se tenham despesas maiores que as receitas.

\section{Como o senhor classifica o mode- lo atual de gestão dos clubes?}

$\mathrm{Na}$ maioria dos clubes, o modelo adotado é inadequado, mas já há alguns com modelos mais aprimorados. A meu ver, como os clubes, de acordo com seus estatutos, não podem ou não devem ser transformados em empresas, o estatuto e o sistema poderiam ser iguais. Por exemplo, haveria colaboradores, como os diretores e o vice-presidente de departamento, e, subordinado a eles, um executivo especializado na área de cada departamento. Adaptando o sistema ao clube, teríamos o diretor financeiro do clube colaborador e um diretor financeiro profissional; no departamento de futebol, teríamos um diretor de futebol e, subordinado a ele, um diretor de futebol profissional, e aí por diante. Assim, seria possível criar sistemas de apoio aos diretores colaboradores que fossem bons dirigentes.

Outra característica presente no atual modelo, que a meu ver deveria ser modificada, é a de os clubes de futebol, em sua maioria, serem clubes sociais. Eles são formados por um conselho que elege o presidente. A gestão social dos clubes é responsável pelo sistema político que os envolve. Na maioria dos clubes houve, numa determinada épo$c a$, a venda de títulos associativos, e esses associados têm direito a ser el eitos por um consel ho, que por sua vez elege um presidente. A única forma de se profissionalizar esse processo seria separar o departamento de futebol dos demais departamentos do clube, elicenciá-lo para que possa ser gerido separadamente.

\section{Com esse modelo, quais os clubes que apresentam boas administra- ções?}

0 que se destaca mais é o São PauIo, que tem uma gestão extremamente profissionalizada e uma estrutura extremamente forte. Você ainda tem o Atlético-PR se direcionando para isso, e há também o Santos e o Goiás. Salvo engano, esses são os melhores exemplos.

\section{De que forma os clubes poderiam aproveitar melhor suas fontes de renda?}

É difícil responder a esta questão. Primeiro, para se fazer al go além da venda de jogadores, que continua sendo a grande receita do futebol brasileiro, seria necessário um investimento prévio, e os clubes não estão suficientemente capitalizados para tal investimento. A primeira receita ainda é proveniente da televisão. Felizmente, a tel evisão tem valorizado os clubes. A segunda receita viria dos patrocínios. Cada vez mais, se houver um campeonato bem equilibrado, com ótimas transmissões, as camisas se valorizam. Temos camisas que são vendidas a $\mathrm{R} \$ 15$ milhões por ano, e no contexto brasileiro isso significa uma boa receita. Dessa forma, os patrocínios de modo geral ocupam um forte espaço na receita. Além disso, há as receitas de jogos, que também começam a ocupar um espaço que haviam perdido há algum tempo, conseqüência da melhoria dos estádios. 0 campeonato de pontos corridos começa a surtir efeito porque se sabe quando é o jogo, e podem se fazer promoções. Tudo isso integra um esforço para aumentar o faturamento. M as seria importante ter um ótimo profissional na área de Marketing Esportivo para poder utilizar todas as situações que o clube oferece para explorar a venda de patrocínio ou a venda de publicidade, e gerenciar a marca para se conseguirem receitas crescentes. Essas têm aumentado muito no Brasil. O s clubes começaram a dar crédito não apenas à venda de jogadores, mas também a essas receitas alternativas. A pesar disso, é fundamental que haja um Departamento de Marketing eficiente que infelizmente poucos clubes têm.

Os clubes podem caminhar sozinhos em direção a um modelo profissional ou é necessário que se unam?

Eles têm caminhado sozinhos. 0 Clube dos 13 não tem conseguido 
bons resultados. Ele tem feito avanços, sem dúvida, e poderiam até ser melhores, se houvesse mais unidade. Mas já melhorou muito. 0 caminho é haver mais unidade, porque em conjunto se pode negociar melhor do que individual mente.

Nesse aspecto, a tentativa de clubes como Corinthians, São Paulo e Flamengo negociarem suas cotas de transmissão dos jogos à parte seria algo positivo ou negativo?

Eu desaconselho essa estratégia. A meu ver, o melhor caminho ainda é a negociação em conjunto. Primeiro porque o campeonato precisa de todos, e se a maior parte da receita ficar com pou cos clubes, o campeonato perde tecnicamente e em termos de competitividade. É o caso da I tália, por exemplo, em que ficam três equipes disputando o campeonato e o restante não apresenta as mesmas condições. Por isso, essas negociações com a tel evisão devem ser feitas em conjunto, e cada clube deveria ter um Departamento de $M$ arketing atuante que buscasse as receitas alternativas em função do seu trabalho.

O fato de exportarmos cada vez mais jogadores para o futebol europeu é um alerta de que estamos nos tornando, ou já nos tornamos, apenas um centro de formação de jogadores?

Isso não é um alerta, mas uma realidade de que há muitos anos nos tornamos um centro formador. $N$ ão tenho certeza se isso é ruim ou não, porque a Holanda também é um centro formador. Seus principais jogadores não jogam no país. A diferença é que o futebol brasileiro vende muito cedo seus jogadores, mas também traz alguns jogadores exportados de volta. Ele tem conseguido fazer esse balanceamento.
Evidentemente o ideal seria a manutenção do jogador no país por mais tempo. A saída é inevitável, até pelas condições financeiras do país. Então, o melhor seria negociar bem o campeonato, criar situações que inibam a saída durante o campeonato. Poder-se-ia estabelecer um prazo de inscrição até $x$ dias antes do campeonato, com outro prazo para venda no fim do primeiro turno. Assim se evitaria o desmantelamento dos times durante o campeonato.

\section{Isso coincide com a mudança pre-} tendida pela CBF de adaptar o calendário nacional ao calendário europeu. Você acredita que é uma boa proposta?

Acredito que sim. Isso inibiria um pouco mais a saída dos jogadores. Também ficamos com um calendário gl obalizado, o que é importante até em termos de Seleção Brasileira. Acredito que há mais vantagens do que desvantagens.

De uma perspectiva administrativa, em que aspectos o futebol europeu pode servir como exemplo? A meu ver podem ser citados exemplos em três níveis. 0 primeiro, de âmbito nacional, onde a Inglaterra surge como um bom exemplo, porque ela aproveita todos os mecanismos do marketing esportivo para incrementar suas receitas. Lá os clubes negociam bem com a televisão, têm uma restrição a jogadores estrangeiros, por isso atraem os meIhores, aproveitam muito bem 0 licensing, vendem produtos, e os ingressos são bastante valorizados. Acredito que a Inglaterra é um ótimo exemplo pelo planejamento financeiro, pela reformulação da legislação sobre o futebol e pela reorganização dos estádios. 0 segundo, no âmbito dos clubes; o time do Barcelona é um bom exemplo. É um clube esportivo, como os clubes no Brasil, mas é interessante notar que os diretores conseguem geri-lo de uma forma profissional, o que falta nos clubes brasileiros. I sso sem descuidarmos de fazer as adaptações necessárias para o contexto brasileiro. 0 terceiro exemplo, no âmbito dos eventos, é a C hampions League. Ela pode inspirar modificações na formatação da organização da Libertadores, por exemplo, sempre resguardando as características próprias dos contextos nacionais.

\section{Com base nas diretrizes que devem} guiar a administração dos clubes, fazer parcerias é uma boa prática ou pode representar um retrocesso?

Acredito que a parceria é uma ótima prática. Penso que a mais bemsucedida, que foi a PalmeirasParmalat, é um modelo que ainda poderia ser usado, com al guns aperfeiçoamentos. 0 que tem dado muito errado no Brasil são os investidores. Como experiências que não deram certo podem ser citadas a parceria com o Nations Bank no Vasco da Gama, com a ISL no Grêmio e no Flamengo, e com a Hicks Muse no Corinthians e no Cruzeiro. Hoje temos a MSI no Corinthians com sérios problemas porque sua principal fonte de renda é proveniente da venda de jogadores. E o mercado da venda de jogadores, em comparação com épocas anteriores, não é tão lucrativo. Então o investidor possui apenas um ativo, que éa venda de jogador. 0 licensing é muito pequeno e não permite um retorno adequado. Por isso, acredito que o relacionamento com o investidor ainda é complexo.

Como alternativa, a parceria é uma boa estratégia porque envolve responsabilidades praticamente iguais de ambas as partes, do investidor e do clube, com condições cla- 
ras do que cabe a cada um fazer. $\mathrm{E}$ uma empresa que necessite de publicidade pode preferi-la em troca dos ganhos financeiros, que foi 0 caso da Parmalat. N esse caso, o desempenho do time é preservado porque há bem menos chances de que alguma venda de jogador ocorra às vésperas de algum campeonato ou jogo, como acontece com o atual modelo de financiamento.

\section{N esse caso, são os investidores que incentivam a venda de jogadores para depois lucrar com ela ou são os clubes que apenas oferecem isso?} Acredito que se cometeram dois erros claros com os investidores. 0 primeiro é que eles desconheciam total mente o mercado brasileiro de futebol, acharam que venderiam jogadores a cada dois meses. E o segundo foi dos clubes, que tiveram o capital e não o geriram adequadamente. $\mathrm{E}$ aí pode ser citado mais um erro dos investidores, que foi não colocarem uma pessoa de sua confiança na administração dos clubes. Adicionalmente, desconsideraram que a gestão de clube no Brasil é de caráter mais emocional do que racional.

\section{Q ual a sua opinião sobre os cursos de gestão esportiva?}

Acredito que são muito importantes porque dessa forma há a preparação de profissionais para atuar nesse segmento. Um obstáculo é que ainda é muito difícil para os profissionais ingressarem nos clubes devido à existência de "feudos". A tendência é que esses "feudos" sejam desmantelados porque será o profissionalismo que irá sustentar os clubes. Uma característica a ser levada em conta é que a organização esportiva é muito difícil, muitas vezes até mais do que a de uma empresa. 0 equilíbrio entre emoção e razão é primordial porque não se pode ficar sem nenhum dos dois, e o mundo dos sonhos - de trabalhar no seu clube pode se transformar em pesadel 0 . Infelizmente as pessoas consideram 0 esporte de maneira muito frívola.

Uma crítica que faço é que em muitos dos cursos os professores não são preparados nem capacitados para lecionar. 0 que às vezes ocorre são profissionais que não têm a mínima noção do esporte e acreditam que podem administrar o esporte sem nenhuma vivência, apenas transpondo conceitos e técnicas da administração para a gestão esportiva. Há problemas muito específicos de gestão do futebol que não são alcançados por essa abordagem livresca. Para evitar isso, aconselho os alunos dos cursos a não esquecerem da vivência, de realizar estágios, de ir aos clubes, de pegar uma fila de ingresso para entender o problema do torcedor. Porque ficar no computador acessando Internet e conhecendo como funciona em outros lugares dá acesso apenas a uma pequena parte de todo o universo do futebol. A grande questão para esses cursos e para o futuro gestor é a incorporação dos problemas concretos por meio da prática.

\section{ANTÔNIO CARLOS KFOURI AIDAR}

\section{Em sua opinião, qual é o maior pro- blema do futebol brasileiro?}

Basicamente, o problema maior dos clubes, e isso é antiqüíssi mo, éa falta de profissionalismo na gestão. Isso não quer dizer necessariamente que os atuais gestores não poderiam ser eles mesmos os gestores dos clubes, mas é muito difícil se imaginar que al guém possa gerir eficazmente se não for remunerado. $\mathrm{E}$ talvez isso seja o início do problema. A gestão dos clubes brasileiros provém de uma tradição em que os car- gos de diretores são pro bono, não são remunerados. Faço questão de deixar isso bem claro, porque profissionalizar não significa somente tirar todo mundo que já está no clube e colocar um quadro novo. Vários clubes têm diretores muito bons, só que el es têm problemas porque não podem ser remunerados. Nessas condições, como é que uma pessoa pode se sustentar e sustentar sua família? Ou essa pessoa possui recursos financeiros suficientes para se sustentar ou ela fica apenas três horas por dia no clube e não consegue resolver seus problemas. Assim, dificilmente se conseguirá um al to grau de profissionalismo de gestão.

\section{Há algum outro problema adicional?}

Sim, há um segundo problema: a mistura da paixão com a razão. Acredito que a paixão no futebol é o coração do esporte, mas ela tem que permanecer dentro de campo. A gestão precisa ser feita com razão. E é muito difícil fazer essa separação. Os clubes precisam ser administrados como empresas, em que não se pode gastar mais do que se recebe. No futebol brasileiro, a grande maioria dos clubes é administrada com a paixão enão com a razão orientada para a eficiência econômica.

Há ainda um terceiro problema, relacionado com a tradição histórica recente. Antigamente os clubes não eram endividados, mas hoje, com raríssimas exceções, estão totalmente endividados. Isso porque, ao longo da década de 1980 e início da década de 1990, houve o início de uma transição financeira no futebol. Os volumes financeiros anteriores a esse período eram muito pequenos. Um exemplo: o Sócrates e o Zico, quando foram para a Seleção em 1982, ganhavam cada um cerca de 5 ou 6 mil dólares por mês. 
Atualizando esses valores, mesmo que se corrija com a inflação do dólar, serão aproximadamente $14 \mathrm{mil}$ ou 15 mil dólares por mês. Um jogador de destaque hoje gan ha muito mais do que isso.

\section{Então, o que mudou?}

A partir das décadas 1980-1990 o futebol começou a movimentar um volume de dinheiro inexistente anteriormente. 0 que acontecia entre 1950-1960, quando o clube era gerido com poucos recursos financeiros, era que os próprios dirigentes faziam uma "vaquinha" e pagavam as contas quando faltava dinheiro. Isso hoje é inviável. Os valores ficaram tão altos que essa paixão de querer pagar para ter o jogador no seu time e não conseguir ter receita levou os clubes a essa enorme dívida. A tel evisão e os patrocinadores entraram com montantes consideráveis de dinheiro, mas que foram utilizados quase que exclusivamente para o pagamento de jogadores.

Por conta disso, os nossos jogadores começaram a sair do Brasil cada vez mais, e é um fenômeno que não controlamos. Por quê? Devido ao poder do dinheiro. Um contrato de televisão no Brasil hoje vale US\$ 120 milhões, US\$ 150 milhões, dependendo da cotação do dólar. $\mathrm{Na}$ Premier League, na Inglaterra, esse mesmo contrato vale US\$800 miIhões. É obvio que a questão da receita mudou completamente o mundo do futebol. Pode ser citado um exemplo que usamos no nosso curso de gestão e que é bem ilustrativo. Projeta-se uma imagem da final da Copa do Mundo de 1958 e uma da final da Copa de 2002, e se pergunta aos alunos qual é a principal diferença entre elas. Uns falam que é a velocidade do jogo, outros o sistema de marcação. $\mathrm{N}$ a verdade, em 1958 não tínhamos uma placa de publicidade no campo, o que ocorre intensamente em 2002. Essa foi a grande mudança, e foi muito rápida. $\mathrm{Na}$ Europa isso também aconteceu. Se olharmos a Inglaterra nos anos 1980, não difere muito do que acontecia no Brasil. A grande mudança na Inglaterra aconteceu em 1989, após o Relatório Taylor, que obrigou a Inglaterra a modificar os seus estádios por causa de vários incidentes, um em especial, o de Hillsborough, onde morreram 90 ingleses pisoteados em um campo de futebol. A partir desse ponto, os estádios viraram fontes de geração de receita, al ém da televisão.

\section{Quais são as estratégias para se aumentar a receita dos clubes?}

Basicamente há dois caminhos. 0 primeiro é a tel evisão; mas enquanto permanecer o monopólio da Rede Globo, a situação dificilmente se modificará. E como ela paga o quanto quer, então já há um problema. 0 segundo caminho são as arenas esportivas. $M$ as para se fazer essas arenas é preciso primeiro o financiamento, e não há atual mente financiadores dispostos a isso. Talvez uma saída seja a Copa de 2014, que deverá ser no Brasil, e que obrigará que se reformem pelo menos 10 estádios. Isso se fará com recursos externos ou com auxílio do governo.

0 estádio pode ser uma fonte de receitas não apenas nos dias de jogos, mas nos dias sem jogos. Tomese o modelo europeu e especialmente $o$ do $M$ anchester United, que possui diversos camarotes no seu estádio alugados normal mente a empresas. E as empresas utilizam esses camarotes todos os dias para fazer suas reuniões de consel ho, reuniões de diretoria, etc. Outro exemplo: imagine um jogo de Libertadores da América. Morumbi com 55 mil pessoas. São 55 mil pessoas no estádio que precisam comer antes ou depois do jogo, porque no interior do estádio não há lugar. Imagine se dentro do estádio você tivesse, como na Europa, a possibilidade de alimentar essas pessoas. Imagine quanto dinheiro poderia ser arrecadado pelo grupo mandante do jogo se ele tivesse um sistema adequado de alimentação dentro do estádio. Agora, novamente, tudo isso só é possível apenas com financiamentos iniciais.

\section{Seria uma solução desvincular toda a estrutura do futebol da parte so- cial dos clubes?}

Sem dúvida. Acredito que não é possível misturar as duas coisas. Entretanto, isso por si só não resolve. A receita não será gerada dessa forma. O sistema de gestão é uma combinação de vários el ementos. Quanto à separação da parte social, estou plenamente de acordo, mas que isso seja somado à profissionalização. É necessário que os vários fatores sejam abordados conjuntamente. É preciso que a televisão dispute e pague para transmitir os jogos; é também necessário ter a arena como geradora de receita, e assim por diante. Numa Ioja, se o vendedor não receber bem o cliente, este dificilmente retornará. No estádio, o torcedor é mal-tratado, sequer tem lugar reservado, mas a paixão é tão grande que ele retorna. As classes média e média al ta não vão ao estádio porque têm medo de assal to; não há segurança suficiente, sequer lugar marcado, não há banheiros adequados e assim por diante. Mas se pode argumentar que, se forem feitas reformas nos estádios, muitos dos torcedores não poderão mais assistir aos jogos por conta do aumento dos ingressos. A meu ver, essa afirmação não é verdadeira. 0 que poderia acontecer é haver diferentes preços dentro do estádio. Os 
clubes deverão ter estádios na faixa de 40 a 70 mil pessoas, funcionando com a lotação quase completa, e em jogos de finais com lotação total. $E$, dentro desses números, é necessário reservar uma parte dos ingressos a preços acessíveis; outra parte dos ingressos será mais cara, para se ter o retorno do investimento, seja nos camarotes, que podem ser alugados para as empresas, seja em assentos que serão mais caros. Então, são diversas as mudanças que devem ser feitas para se conseguir aumento de receitas para o financiamento dos clubes.

\section{No Brasil, quais os clubes que apresentam um modelo de gestão exemplar?}

É uma questão difícil. Nenhum modelo me agrada totalmente. O São Paulo tem dívidas, é bem gerido, está em primeiro lugar, mas não apresenta o modelo ideal de gestão. Enquanto não tiverem uma gestão mais profissionalizada, os clubes sempre terão disputas el eitorais, e muitas vezes essas disputas fazem com que os adversários el eitorais torçam para que o time perca. $E$ isso é um absurdo. 0 sistema é um equívoco.

Baseando-se no futebol europeu, qual é o melhor exemplo para termos como base?

Simpatizo com o modelo de gestão de alguns clubes ingleses. 0 $M$ anchester é o clube mais bem gerido, trabalha com orçamento como uma empresa. $\mathrm{N}$ ão é à toa que se tornou um dos maiores clubes do mundo. 0 exemplo é claro: não se pode gastar mais do que se recebe. Se for considerar a receita operacional, nenhum time brasileiro consegue faturar mais de $R \$ 60$ ou 70 milhões. Com isso, os clubes brasileiros não podem e não conseguem concorrer com a Europa. Para se ter os jogadores de destaque no país são necessários uma boa gestão e 0 aumento das receitas. E para aumentar as receitas é preciso mudar o sistema de venda à tel evisão e, ao mes- mo tempo, obter receita com os estádios. Essa é uma mudança para no mínimo 10 anos, isso se começarmos hoje, mas esse movimento ainda não se iniciou.

Nesse ponto, fazer parcerias é uma boa solução?

Acredito que as parcerias até hoje, infelizmente, foram muito mal construídas, com exceção da PalmeirasParmalat. Temos hoje o caso do Corinthians. Como o clube faz uma parceria em que o interesse não é comum? Vejo isso como um problema extremamente complexo. Qual 0 interesse da MSI? Lucrar com o Corinthians. É possível ganhar dinheiro operacionalmente no Brasil? Não. A MSI sozinha não consegue aumentar a televisão, pode aumentar o patrocínio. Isso el a conseguiu. Como a MSI vai lucrar? $\mathrm{Na}$ venda de jogadores. Esse tipo de parceria funciona para clubes pequenos, mas as grandes marcas não podem e não conseguem sobreviver apenas com essa forma de fonte de renda.

\section{Artigo convidado. Aprovado em 28.04.2006.}

